Original Article

\title{
Effects of phase I complex decongestive physiotherapy on physical functions and depression levels in breast cancer related lymph edema
}

\author{
Orçın Telli Atalay ${ }^{1}{ }^{*}$, Anil ÖZkir $^{2)}$, Bilge Başakçı Çalik ${ }^{3)}$, Emre Baskan ${ }^{4)}$, Harun Tașkin ${ }^{1)}$ \\ 1) Department of Physiotherapy and Rehabilitation, School of Physical Therapy and Rehabilitation, \\ Pamukkale University: Denizli, Turkey \\ 2) Department of Physiotherapy and Rehabilitation, Institute of Health Sciences, Pamukkale University, \\ Turkey \\ 3) Department of Orthopedical Rehabilitation, School of Physical Therapy and Rehabilitation, \\ Pamukkale University, Turkey \\ 4) Department of Neurological Rehabilitation, School of Physical Therapy and Rehabilitation, \\ Pamukkale University, Turkey
}

\begin{abstract}
Purpose] Breast cancer-related upper extremity lymph edema is known to cause physical, functional and psychological impairments in women after modified radical mastectomy. The aim of this study was to investigate the effects of phase I Complex Decongestive Physiotherapy (CDP) on physical functions and depression levels in women with breast cancer-related upper extremity lymph edema. [Subjects and Methods] Fifty-eight subjects with breast cancer-related upper extremity lymph edema were the subjects of this study. The arm circumference, shoulder range of motion (ROM), muscle strength and depression levels of the subjects were assessed before and after phase I CDP treatment. [Results] After phase I CDP, there was a statistically significant reduction in circumference measurements at all levels of the affected arm. There was not any statistically significant difference in muscle strength after CDP. The shoulder ROM improved after treatment. There was a significant reduction in the Beck Depression Inventory score. A significant positive correlation was found between depression levels and circumference measurement. [Conclusion] Based on the results we suggest that by reducing limb volume, beside improving physical functions, phase I CDP can affect psychological status, especially depression which is very common in women with breast cancer-related upper extremity lymph edema.

Key words: Lymph edema, Complex decongestive physiotherapy, Depression
\end{abstract}

(This article was submitted Sep. 25, 2014, and was accepted Nov. 7, 2014)

\section{INTRODUCTION}

Lymph edema is the accumulation of a high-protein edema fluid in the interstitial tissue as a result of the functional overload of the lymphatic system in which lymph volume exceeds transport capabilities and the lymphatic system becomes overwhelmed, causing lymphatic insufficiency or failure ${ }^{1)}$.

Primary lymph edema may be caused by the congenital and/or hereditary etiology. Secondary lymph edema may occur as a result of obstruction or interruption of the lymph system due to surgery. Also radiotherapy, trauma, infection, malignancy and chronic venous insufficiency. The most common cause of secondary lymph edema in the upper

*Corresponding author. Orçin Telli Atalay (E-mail: orcint@ pau.edu.tr)

(C2015 The Society of Physical Therapy Science. Published by IPEC Inc. This is an open-access article distributed under the terms of the Creative Commons Attribution Non-Commercial No Derivatives (by-ncnd) License $<$ http://creativecommons.org/licenses/by-nc-nd/3.0/>. extremity is breast cancer treatment, especially with the combination of axillary surgery and radiation and lower extremity lymph edema mostly occurs as a consequence of gynecological cancer (cervical, endometrial, vulvar, head and neck cancers) ${ }^{2}$.

The prevalence of post breast cancer surgery upper limb lymph edema is between $8 \%$ and $65 \%$ as described in the literature ${ }^{3,8)}$. The main reasons for this wide reported range of prevalence of the upper extremity lymph edema are: the follow-up time, the number of patients included in the studies, the classification and criteria used for its definition, the use of different measuring methods, and the time elapsed after surgery.

The factors that contribute to the development of upper extremity lymph edema after breast cancer surgery are classified in terms of extent of axillary surgery and mastectomy, axillary lymph node dissection (ALND), the number of nodes removed, the presence of a metastatic lymph node, use of axillary radiation therapy, chemotherapy, younger age at diagnosis, older age $(>55)$, weight, body mass index (BMI), injury or infection in the ipsilateral arm, and trauma ${ }^{3-12)}$.

Except for lymph edema the other complications after 
breast cancer surgery are as follows: pain in the affected shoulder and arm, restrictions of shoulder motions, decrease in the muscle strength and functional capacity of the upper extremity, and difficulty with activities of daily living ${ }^{12-16)}$. Development of lymph edema after breast cancer surgery increases the upper extremity symptoms of pain, numbness, stiffness, loss of strength and function ${ }^{5,17)}$.

Together with physical and functional inabilities, lymph edema is also associated with psychological morbidity ${ }^{13)}$. Psychological impacts of lymph edema include anxiety, depression, loss of body self confidence, social isolation and sexual dysfunction ${ }^{18)}$. Moreover lymph edema and impaired upper extremity functions lead to deterioration in the activities of daily living ${ }^{16)}$. It is reported that the functions of the arm decrease as the severity of lymph edema increases and the levels of depression and anxiety increase as the symptoms of the upper extremity increase ${ }^{19,20)}$. The severity and localization of lymph edema and pain are the factors that aggravate psychological distress and anxiety ${ }^{13)}$. There are several methods of treatment for breast cancer-related lymph edema including physiotherapy, exercises, medical treatment with benzopyrones and a variety of microsurgical techniques. Complex decongestive physiotherapy (CDP) is a multimodality approach that consists of manual lymphatic drainage (MLD), skin care, compression bandages, and exercise, and it is a promising form of treatment recently. CDP is used to activate lymphatic vessels and move protein rich fluid from edematous to non edematous areas. Although CDP was developed several decades ago, there are many studies that show CDP can greatly reduce the volume and percentage volume of breast cancer-related lymph edema. However, there are few studies about the effects of CDP on other physical aspects such as pain, restriction of movements, and functions of the upper extremity or its effects on psychological factors. Therefore the aim of this study was to investigate the effects of phase I CDP on physical functions and depression levels of subjects with breast cancer-related upper extremity lymph edema.

\section{SUBJECTS AND METHODS}

This interventional clinical study was carried out at Pamukkale University School of Physical Therapy and Rehabilitation. Approval for this study was granted by the non-invasive clinical research ethics committee of Pamukkale University and the study was conducted in accordance with the principles of the Declaration of Helsinki. All the subjects provided their informed consent.

Among the 96 subjects having lymph edema and referred for physical therapy, 77 subjects with secondary lymph edema after modified radical mastectomy were chosen. The subjects who had metastasis, severe orthopedical or neurological deformity, acute infection, uncontrolled hypertension, severe venous or arterial insufficiency, severe psychiatric symptoms or any other contraindications to manual lymphatic drainage and compression were excluded. Sixtythree subjects met the inclusion criteria of this study, but five of the subjects did not attend to the decongestive physical therapy programme regularly and they were excluded from the assessments. Therefore, the data of 58 subjects forms the basis of this study.

Circumference, range of motion (ROM) measurements of both upper extremities, muscle strength of the ipsilateral extremity and depression level were assessed before and after the phase I CDP treatment.

The circumferences of both extremities were measured at the metacarpophalengeal joints of the hand, and styloid process of radius and 5,10 , and $15 \mathrm{~cm}$ above the styloid process of radius of the forearm, the lateral epycondile and 5,10 , and $15 \mathrm{~cm}$ above the lateral epycondile of the upper arm by using a standard one inch, retractable, fiber glass tape measure. The measurements were done twice, each time by the same physiotherapist ${ }^{21)}$.

The shoulder range of motion was measured using standard techniques of goniometry as active and passive measurements of shoulder flexion, extension, abduction and adduction, internal and external rotation ${ }^{21,22)}$. Muscle strength of the ipsilateral extremity was measured by Lovett's manual muscle testing ${ }^{23)}$.

Depression levels of the subjects were evaluated using the Beck Depression Inventory (BDI) which was first developed by Beck et al. in 196124). There are 21 categories; each of which has four options. Participants were asked to choose the suitable option that expressed their emotional status in the last 1 -week period. The maximum score is 63 , and the cutoff value for the Turkish version is 17 which indicates a need for help ${ }^{25)}$.

Phase I Complex Decongestive Physiotherapy consisting of MLD, multi layer compression bandaging, remedial exercises in combination with respiratory exercises were performed by all subjects five times in a week for four weeks (20 sessions in total) by a certified lymph edema physiotherapist $^{21,26-28)}$. At the end of the phase I CDP treatment the subjects wore compression garments. Self massage, home exercises for lymph edema and skin care were prescribed for the subjects by the therapist for the phase II CDP.

Analyses of data were performed using SPSS for Windows version 16.00. Differences in measurements circumference, shoulder range of motion and the Beck Depression Inventory were assessed using the paired samples $t$ test. Pearson's correlation coefficient method was used to assess the influence of changes in measurement of circumference and shoulder range of motion on Beck Depression Inventory scores. $\mathrm{P}$ values $<0.05$ were considered as statistically significant.

\section{RESULTS}

The physical characteristics and demographic data of subjects are presented in Table 1. The dominant extremities of twenty-eight subjects were affected. Fifty-one of the subjects had been given chemical therapy (CT), 43 of subjects had been given radiotherapy (RT) and 38 of subjects had received endochirine therapy (Table 2). The average duration of lymph edema was $32.0 \pm 5.5$ months and the average time since the operation was $38.5 \pm 2.1$ months. The average number of dissected lymph nodes was $11.1 \pm 1.8$. After modified radical mastectomy, the subjects were given on averagely $5.3 \pm 1.1$ treatments of CT and $10.2 \pm 4.0$ sessions of RT. A significant difference in the circumference measurement was 
Table 1. Physical properties and demographic data of the subjects

\begin{tabular}{llc}
\hline Physical properties & & $\mathrm{X} \pm \mathrm{SD}$ \\
\hline Age $($ years $)$ & & $43.5 \pm 5.3$ \\
Height $(\mathrm{cm})$ & & $161.3 \pm 6.7$ \\
Weight $(\mathrm{kg})$ & & $78.4 \pm 7.8$ \\
BMI $\left(\mathrm{kg} / \mathrm{m}^{2}\right)$ & & $26.3 \pm 1.2$ \\
\hline Demographic data & & $\mathrm{N}(\%)$ \\
Education level & Illiterate & $15(25.8)$ \\
& $<8$ years & $27(46.5)$ \\
& $>8$ years & $16(27.5)$ \\
Occupation & Housewife & $35(60,34)$ \\
& Teacher & $13(22.4)$ \\
& Retired & $10(17.2)$ \\
\hline
\end{tabular}

Table 3. Comparison of upper extremity circumference measurements

\begin{tabular}{lcc}
\hline $\begin{array}{l}\text { Circumference } \\
\text { Measurement }\end{array}$ & B.CDP $(\mathrm{cm})$ & A.CDP $(\mathrm{cm})$ \\
\hline MCP joint & $21.3 \pm 0.8$ & $20.0 \pm 1.2$ \\
Styloideus Radius $^{*}$ & $22.5 \pm 4.3$ & $20.9 \pm 0.9$ \\
$5 \mathrm{~cm} \uparrow^{*}$ & $26.4 \pm 4.7$ & $23.6 \pm 2.5$ \\
$10 \mathrm{~cm} \uparrow^{*}$ & $27.0 \pm 5.1$ & $24.7 \pm 7.3$ \\
$15 \mathrm{~cm} \uparrow^{*}$ & $29.2 \pm 4.7$ & $26.7 \pm 5.3$ \\
Lateral Epicondyles & $30.9 \pm 3.9$ & $29.2 \pm 3.6$ \\
$5 \mathrm{~cm} \uparrow^{*}$ & $36.7 \pm 6.3$ & $32.3 \pm 6.8$ \\
$10 \mathrm{~cm} \uparrow^{*}$ & $37.0 \pm 7.7$ & $33.9 \pm 5.4$ \\
$15 \mathrm{~cm} \uparrow^{*}$ & $38.8 \pm 3.3$ & $34.0 \pm 2.9$ \\
\hline
\end{tabular}

$* \mathrm{p}<0.05$, MCP: metacarpophalengeal

B.CDP: Before Complex Decongestive Physiotherapy

A.CDP: After Complex Decongestive Physiotherapy

Table 5. Comparison of depression scores

\begin{tabular}{lcc}
\hline Depression score & B.CDP & A.CDP \\
\hline BDI $^{*}$ & $24.5 \pm 5.4$ & $19.4 \pm 8.3$ \\
\hline$* \mathrm{p}<0.05$, B.CDP: & Before Complex & Decongestive \\
Physiotherapy & & \\
A.CDP: After Complex Decongestive Physiotherapy
\end{tabular}

found when compared before and after complex decongestive physiotherapy (CDP) at all levels of measurement (Table 3). We found that the muscle strength of the subjects was good (average 4.6 \pm 0.2 according to manual muscle testing) and decrease in muscle strength was not found before CDP. The shoulder range of motions before and after CDP are shown in Table 4. According to this table, a significant difference was found in all shoulder range of movements except from adduction. Although active shoulder range of movement did not reach to normal levels, there was a significant increase after CDP. When we assessed the average depression scores of the subjects before CDP a moderate level of depression was found. The depression score improved to mild depression levels after CDP and there was a significant difference
Table 2. Other therapies that subjects received after MRM

\begin{tabular}{llr}
\hline Other therapies & & $\mathrm{N}(\%)$ \\
\hline Chemical therapy & Yes & $51(87.9)$ \\
& No & $7(12.0)$ \\
Radio therapy & Yes & $43(74.1)$ \\
& No & $15(25.8)$ \\
Endocrine therapy & Yes & $38(65.5)$ \\
& No & $20(34.4)$ \\
\hline
\end{tabular}

Table 4. Comparison of upper extremity range of motions

\begin{tabular}{llcr}
\hline ROM & & B.CDP $\left({ }^{\circ}\right)$ & A.CDP $\left({ }^{\circ}\right)$ \\
\hline Shoulder & Flexion* & $136.6 \pm 9.6$ & $171.3 \pm 8.2$ \\
joint & Extension $^{*}$ & $54.6 \pm 5.7$ & $58.6 \pm 6.2$ \\
& Abduction $^{*}$ & $128.3 \pm 16.4$ & $164.9 \pm 2.3$ \\
& Adduction & $0.0 \pm 0.0$ & $0.0 \pm 0.1$ \\
& Internal rotation $^{*}$ & $78.8 \pm 4.6$ & $85.5 \pm 1.0$ \\
& External rotation $^{*}$ & $76.4 \pm 2.4$ & $84.2 \pm 3.6$ \\
Elbow & Flexion & $142.6 \pm 8.9$ & $146.0 \pm 9.6$ \\
joint & Extension & $0.0 \pm 0.0$ & $0.0 \pm 0.0$ \\
Wrist & Flexion & $85.5 \pm 2.5$ & $85.9 \pm 3.4$ \\
joint & Extension & $84.8 \pm 0.8$ & $85.3 \pm 3.8$ \\
& Ulnar deviation & $19.6 \pm 0.3$ & $21.0 \pm 2.6$ \\
& Radial deviation & $14.4 \pm 1.9$ & $15.6 \pm 2.3$ \\
\hline
\end{tabular}

$* p<0.05$, ROM: range of motion

B.CDP: Before Complex Decongestive Physiotherapy

A.CDP: After Complex Decongestive Physiotherapy

Table 6. Relation between average change in depression measurement and average change in circumference measurements of the affected arm

\begin{tabular}{lll}
\hline $\begin{array}{l}\text { The average change in } \\
\text { depression scores } \\
(\mathrm{X} \pm \mathrm{SD})\end{array}$ & $\begin{array}{l}\text { The average change in circum } \\
\text { ference measurements of the } \\
\text { affected arm } \\
(\mathrm{X} \pm \mathrm{SD})(\mathrm{cm})\end{array}$ & $\mathrm{r}$ \\
\hline$\Delta$ BDI score & $\Delta \mathrm{MCP}$ joint $(1.0 \pm 0.8)^{*}$ & 0.4 \\
$(5.6 \pm 1.4)$ & $\Delta$ Styloideus radius $(2.2 \pm 0.7)^{*}$ & 0.7 \\
& $\Delta 5 \mathrm{~cm} \uparrow(3.4 \pm 0.9)^{*}$ & 0.6 \\
& $\Delta 10 \mathrm{~cm} \uparrow(3.1 \pm 1.1)^{*}$ & 0.7 \\
& $\Delta 15 \mathrm{~cm} \uparrow(3.4 \pm 1.2)^{*}$ & 0.4 \\
& $\Delta$ Lateral epicondyles $(1.0 \pm 0.5)^{*}$ & 0.3 \\
& $\Delta 5 \mathrm{~cm} \uparrow(4.2 \pm 1.2)^{*}$ & 0.6 \\
& $\Delta 10 \mathrm{~cm} \uparrow(2.9 \pm 0.2)^{*}$ & 0.6 \\
& $\Delta 15 \mathrm{~cm} \uparrow(4.0 \pm 1.2)^{*}$ & 0.7 \\
\hline
\end{tabular}

${ }^{*} \mathrm{p}<0.05$, MCP: metacarpophalengeal

in the scores of before and after treatment as shown in Table 5. There was a significant positive correlation between the changes in circumference measurement of the affected arm and the depression level (Table 6). The depression levels decreased as the circumference measurement decreased. 


\section{DISCUSSION}

Psychological and psychosocial factors such as anxiety, depression, distress, altered emotional reactions, sleep disturbances and social isolation are common in breast cancer $^{29)}$. Increased prevalence of depression among breast cancer patients has been shown in several studies ${ }^{30-33)}$. Fann et al. reported that the risk of major depression is $25 \%$ in women with breast cancer, and within one year of diagnosis up to $30 \%$ of women with breast cancer may develop either anxiety or depression, which may persist for more than 5 years after diagnosis and initial treatment ${ }^{34)}$. In one interesting study it was found that those cases of mastectomy and hysterectomy had depressive symptoms and problems regarding body image, spouse relationships and sexual satisfaction. When the depressive state was compared between the cases with mastectomy and hysterectomy, it was found that patients with mastectomy were more depressive than patients with hysterectomy ${ }^{35)}$.

The factors which are related to psychological distress include being diagnosed as having a life-threatening illness, treatments and their side-effects, uncertainty of outcomes, role changes as a result of activity limitation and restrictive participation, and issues related to body image, especially unsatisfactory cosmetic results and lymph edema ${ }^{36,37)}$ There are studies which report that psychological distress such as depression, anxiety; hopelessness and helplessness are more common in breast cancer survivors with lymph edema $^{31-33,38)}$. The study of Khan et al. they found that lymph edema was associated with a higher impact score on the Perceived Impact Problem Profile ${ }^{39}$. In another study, Pyszel et al. reported that breast cancer survivors with lymph edema had statistically significantly worse psychological distress scores than survivors without lymph edema ${ }^{40)}$.

In our study we assessed the depression levels of women with lymph edema after modified radical mastectomy with BDI. In common with the previous studies, we found that women with post mastectomy lymph edema had moderate levels of depression (average BDI score $=24.5 \pm 5.4$ ). The most common symptoms associated with lymph edema are swelling, heaviness, tightness, firmness, pain, numbness, stiffness, decreased mobility, and the physical disfigurement of the condition. Women with post mastectomy lymph edema are unable to complete household responsibilities, in severe cases they even need assistance with daily care activities, and have difficulty in performing their jobs which leads to significant role changes in social life. As a result untreated or occurance of lymph edema is a cause of serious psychological disturbances, e.g. depression. Another reason for the occurance of depression is difficulty with coping and adjusting to a chronic disease, which is for some of the subjects a surprise because of inadequate information. Many of the subjects in our study had the idea that lymph edema was an untreatable condition before complex decongestive therapy, which also might have been a reason for their high levels of depression. Aesthetic concerns, which might prevent women from wearing their usual clothing, might also be an important cause of depression.

The shoulder ROM of women with post mastectomy lymph edema was significantly reduced in our study. There are many studies which indicate that following breast cancer treatment, women with lymph edema present with upper extremity impairments $3,4,13,17,27,28)$. Women with lymph edema more frequently demonstrate bilateral impairments in shoulder ROM and upper extremity strength than women without lymph edema. Besides swelling of the arm, ROM limitation can lead to reduced physical activity which may also be related to depression ${ }^{41,42)}$.

The subjects of our study underwent intensive complex decongestive physiotherapy. Complex physical therapy has been recommended as a primary treatment by consensus panels and is an effective therapy for lymph edema ${ }^{43-47)}$. Complex physical therapy resulted in some volume reduction of the affected extremity in $95 \%$ of 399 patients $(50 \%$ reduction in $56 \%$ of patients, $25-49 \%$ reduction in $31 \%$, and $1-24 \%$ reduction in $8 \%$ ), $54 \%$ of whom maintained the therapeutic result after 3 years ${ }^{48}$ ). In agreement with the literature, the results of our study showed that after CDP, the shoulder ROM of the subjects increased and the circumference measurement of the affected arm significantly decreased.

Several studies have shown the effects of CDP on physical functions and the quality of life of lymph edema patients $\left.{ }^{14}, 15,26-28,47-49\right)$. In one of the literature reviews, researchers concluded that among the therapeutic modalities used for lymph edema treatment, CDP undoubtedly had the strongest scientific support ${ }^{50}$. CDP applied lymph edema patients effectively improved the quality of lymph edema patients through the reduction in the volume and circumference of the affected limb, a decrease in fear of movement, and increase in physical function ${ }^{49}$. As we discussed above, psychological distress such as depression and anxiety, is also associated with lymph edema. Many studies have demonstrated the effectiveness of CDP, however, not many studies have investigated the effects of CDP on depression and other psychological issues. In present study we assessed the depression levels of subjects before and after CDP. We found a significant decrease in the depression score to mildminimum levels. There was a positive correlation between circumference reduction and depression levels and also a negative correlation between ROM and depression levels. We think arm swelling and ROM limitation as a result of lymph edema after mastectomy aggravate depression which is usually found in breast cancer survivors. CDP which is one effective way of treating arm swelling and decrease in physical function can also contribute treatments for psychological distress such as depression.

Reduction in limb volume and increase in range of motion reduces the fear of movement and increase the physical function. The volume decrease in the affected extremity and increase in ROM may lead to improvements in the social roles of subjects through increase of physical function. The improvement in social participation may also be a factor that helps to alleviate depression. Also, a decrease in aesthetic anxiety and becoming aware of that lymph edema is treatable, are the other factors that may contribute to the alleviation of depression.

Our study is important as there are not many studies of the psychological distress in breast cancer and/or lymph edema related to breast cancer, especially secondary lymph edema 
after mastectomy, and there are very few studies about the effects of CDP and other treatment choices on the psychological distress such as depression ${ }^{51,52)}$. The lack of a control group was the most important limitation of this study.

\section{REFERENCES}

1) Kocak Z, Overgaard J: Risk factors of arm lymphedema in breast cancer patients. Acta Oncol, 2000, 39: 389-392. [Medline] [CrossRef]

2) Lawenda BD, Mondry TE, Johnstone PA: Lymphedema: a primer on the identification and management of a chronic condition in oncologic treatment. CA Cancer J Clin, 2009, 59: 8-24. [Medline] [CrossRef]

3) Gärtner R, Jensen MB, Kronborg L, et al.: Self-reported arm-lymphedema and functional impairment after breast cancer treatment-a nationwide study of prevalence and associated factors. Breast, 2010, 19: 506-515. [Medline] [CrossRef]

4) Bergmann A, Koifman RJ, Koifman S, et al.: Upper limb lymph edema following breast cancer surgery: prevalence and associated factors. Lymphology, 2007, 40: 96-106.

5) Hayes SC, Johansson K, Stout NL, et al.: Upper-body morbidity after breast cancer: incidence and evidence for evaluation, prevention, and management within a prospective surveillance model of care. Cancer, 2012 118: 2237-2249. [Medline] [CrossRef]

6) Meeske KA, Sullivan-Halley J, Smith AW, et al.: Risk factors for arm lymphedema following breast cancer diagnosis in Black women and White women. Breast Cancer Res Treat, 2009, 113: 383-391. [Medline] [CrossRef]

7) McLaughlin SA, Wright MJ, Morris KT, et al.: Prevalence of lymphedema in women with breast cancer 5 years after sentinel lymph node biopsy or axillary dissection: patient perceptions and precautionary behaviors. Clin Oncol, 2008, 26: 5220-5226. [Medline] [CrossRef]

8) Lopez Penha TR, Slangen JJ, Heuts EM, et al.: Prevalence of lymphoedema more than five years after breast cancer treatment. Eur J Surg Oncol, 2011, 37: 1059-1063. [Medline] [CrossRef]

9) McLaughlin SA, Van Zee KJ: The prevalence of lymph edema and changes in practice to reduce its occurrence in women with breast cancer. EJCMO, 2010, 2: 1-7.

10) Tsai RJ, Dennis LK, Lynch CF, et al.: The risk of developing arm lymphedema among breast cancer survivors: a meta-analysis of treatment factors. Ann Surg Oncol, 2009, 16: 1959-1972. [Medline] [CrossRef]

11) Özçınar B, Güler SA, Özmen V et al. The complications and their effects on quality of life after local/regional treatment in breast cancer. J Breas Health, 2010, 6: 9-16.

12) Geller BM, Vacek PM, O'Brien $P$, et al.: Factors associated with arm swelling after breast cancer surgery. J Womens Health (Larchmt), 2003, 12: 921-930. [Medline] [CrossRef]

13) Chachaj A, Małyszczak K, Pyszel K, et al.: Physical and psychological impairments of women with upper limb lymphedema following breast cancer treatment. Psychooncology, 2010, 19: 299-305. [Medline] [CrossRef]

14) Lauridsen MC, Christiansen P, Hessov I: The effect of physiotherapy on shoulder function in patients surgically treated for breast cancer: a randomized study. Acta Oncol, 2005, 44: 449-457. [Medline] [CrossRef]

15) Park JE, Jang HJ, Seo KS: Quality of life, upper extremity function and the effect of lymphedema treatment in breast cancer related lymphedema patients. Ann Rehabil Med, 2012, 36: 240-247. [Medline] [CrossRef]

16) Kwan W, Jackson J, Weir LM, et al.: Chronic arm morbidity after curative breast cancer treatment: prevalence and impact on quality of life. J Clin Oncol, 2002, 20: 4242-4248. [Medline] [CrossRef]

17) Smoot B, Wong J, Cooper B, et al.: Upper extremity impairments in women with or without lymphedema following breast cancer treatment. J Cancer Surviv, 2010, 4: 167-178. [Medline] [CrossRef]

18) Shapiro SL, Lopez AM, Schwartz GE, et al.: Quality of life and breast cancer: relationship to psychosocial variables. J Clin Psychol, 2001, 57: 501-519. [Medline] [CrossRef]

19) Ahmed RL, Prizment A, Lazovich D, et al.: Lymphedema and quality of life in breast cancer survivors: the Iowa Women's Health Study. J Clin Oncol, 2008, 26: 5689-5696. [Medline] [CrossRef]

20) Karakoyun-Celik O, Gorken I, Sahin S, et al.: Depression and anxiety levels in woman under follow-up for breast cancer: relationship to coping with cancer and quality of life. Med Oncol, 2010, 27: 108-113. [Medline] [CrossRef]

21) Karadibak D, Yavuzsen T, Saydam S: Prospective trial of intensive decongestive physiotherapy for upper extremity lymphedema. J Surg Oncol, 2008, 97: 572-577. [Medline] [CrossRef]
22) Park SI, Choi YK, Lee JH, et al.: Effects of shoulder stabilization exercise on pain and functional recovery of shoulder impingement syndrome patients. J Phys Ther Sci, 2013, 25: 1359-1362. [Medline] [CrossRef]

23) Lovett RW, Martin EG: Certain aspects of infantile paralysis with a description of a method of muscle testing. JAMA, 1916, 4: 729-733. [CrossRef]

24) Beck AT, Ward CH, Mendelson M, et al.: An inventory for measuring depression. Arch Gen Psychiatry, 1961, 4: 561-571. [Medline] [CrossRef]

25) Hisli N: A study about validity of Beck depression inventory. J Psychol, 1988, 6: 118-122.

26) Hamner JB, Fleming MD: Lymphedema therapy reduces the volume of edema and pain in patients with breast cancer. Ann Surg Oncol, 2007, 14: 1904-1908. [Medline] [CrossRef]

27) Yamamoto R, Yamamoto T: Effectiveness of the treatment-phase of twophase complex decongestive physiotherapy for the treatment of extremity lymphedema. Int J Clin Oncol, 2007, 12: 463-468. [Medline] [CrossRef]

28) Vignes S, Porcher R, Arrault M, et al.: Long-term management of breast cancer-related lymphedema after intensive decongestive physiotherapy. Breast Cancer Res Treat, 2007, 101: 285-290. [Medline] [CrossRef]

29) Fu MR, Ridner SH, Hu SH, et al.: Psychosocial impact of lymphedema: a systematic review of literature from 2004 to 2011. Psychooncology, 2013, 22: 1466-1484. [Medline] [CrossRef]

30) Ewertz M, Jensen AB: Late effects of breast cancer treatment and potentials for rehabilitation. Acta Oncol, 2011, 50: 187-193. [Medline] [CrossRef]

31) McWayne J, Heiney SP: Psychologic and social sequelae of secondary lymphedema: a review. Cancer, 2005, 104: 457-466. [Medline] [CrossRef]

32) Towers A, Carnevale FA, Baker ME: The psychosocial effects of cancerrelated lymphedema. J Palliat Care, 2008, 24: 134-143. [Medline]

33) Ridner SH: The psycho-social impact of lymphedema. Lymphat Res Biol, 2009, 7: 109-112. [Medline] [CrossRef]

34) Fann JR, Thomas-Rich AM, Katon WJ, et al.: Major depression after breast cancer: a review of epidemiology and treatment. Gen Hosp Psychiatry, 2008, 30: 112-126. [Medline] [CrossRef]

35) Keskin G, Gumus AB: Turkish hysterectomy and mastectomy patientsdepression, body image, sexual problems and spouse relationships. Asian Pac J Cancer Prev, 2011, 12: 425-432. [Medline]

36) Taha SA, Matheson K, Anisman H: Everyday experiences of women posttreatment after breast cancer: the role of uncertainty, hassles, uplifts, and coping on depressive symptoms. J Psychosoc Oncol, 2012, 30: 359-379. [Medline] [CrossRef]

37) Brunault P, Suzanne I, Trzepidur-Edom M, et al.: Depression is associated with some patient-perceived cosmetic changes, but not with radiotherapyinduced late toxicity, in long-term breast cancer survivors. Psychooncology, 2013, 22: 590-597. [Medline] [CrossRef]

38) Hack TF, Cohen L, Katz J, et al.: Physical and psychological morbidity after axillary lymph node dissection for breast cancer. J Clin Oncol, 1999, 17: 143-149. [Medline]

39) Khan F, Amatya B, Pallant JF, et al.: Factors associated with long-term functional outcomes and psychological sequelae in women after breast cancer. Breast, 2012, 21: 314-320. [Medline] [CrossRef]

40) Pyszel A, Malyszczak K, Pyszel K, et al.: Disability, psychological distress and quality of life in breast cancer survivors with arm lymphedema. Lymphology, 2006, 39: 185-192. [Medline]

41) Korpan MI, Crevenna R, Fialka-Moser V: Lymphedema: a therapeutic approach in the treatment and rehabilitation of cancer patients. Am J Phys Med Rehabil, 2011, 90: S69-S75. [Medline] [CrossRef]

42) Hayes SC, Janda M, Cornish B, et al.: Lymphedema after breast cancer: incidence, risk factors, and effect on upper body function. J Clin Oncol, 2008, 26: 3536-3542. [Medline] [CrossRef]

43) Földi E, Földi M, Clodius L: The lymphedema chaos: a lancet. Ann Plast Surg, 1989, 22: 505-515. [Medline] [CrossRef]

44) Casley-Smith JR, Foldi M, Ryan TJ, et al.: Summary of the 10th International Congress of Lymphology working group discussions and recommendations. Lymphology, 1985, 18: 175-180.

45) Moseley AL, Carati CJ, Piller NB: A systematic review of common conservative therapies for arm lymphoedema secondary to breast cancer treatment. Ann Oncol, 2007, 18: 639-646. [Medline] [CrossRef]

46) : The diagnosis and treatment of peripheral lymphedema. Consensus document of the International Society of Lymphology Executive Committee. Lymphology, 1995, 28: 113-117. [Medline]

47) Andersen L, Højris I, Erlandsen M, et al.: Treatment of breast-cancer-related lymphedema with or without manual lymphatic drainage-a randomized study. Acta Oncol, 2000, 39: 399-405. [Medline] [CrossRef]

48) Hwang $\mathrm{O}, \mathrm{Ha} \mathrm{K}$, Choi S: The effects of PNF techniques on lymphoma in the upper limbs. J Phys Ther Sci, 2013, 25: 839-841. [Medline] [CrossRef] 
870 J. Phys. Ther. Sci. Vol. 27, No. 3, 2015

49) Kim JK: The long-term effects of complex decongestive physical therapy on lower extremity secondary lymphedema and quality of life. J Phys Ther Sci, 2011, 23: 155-159. [CrossRef]

50) Passik SD, McDonald MV: Psychosocial aspects of upper extremity lymphedema in women treated for breast carcinoma. Cancer, 1998, 83: 2817-2820. [Medline] [CrossRef]
51) Shim JM, Kim SJ: Effects of manual lymph drainage of the neck on EEG in subjects with psychological stress. J Phys Ther Sci, 2014, 26: 127-129. [Medline] [CrossRef]

52) Ha K, Choi S: The effect of a PNF technique program after mastectomy on lymphedema patients' depression and anxiety. J Phys Ther Sci, 2014, 26 : 1065-1067. [Medline] [CrossRef] 